\title{
EKSTRAKSI KULIT BUAH NA GA SEBAGAI ALTERNATIF ZAT PEWARNA ALAMI PADA LIPSTIK
}

\author{
Aninditya Dwi Perwitasaria), Sulhadi ${ }^{\text {b) }}$, Teguh Darsono ${ }^{\text {c) }}$, \\ Susi Agung Purwaningtyas ${ }^{\text {d) }}$, dan Cintia Agtasia Putrie ${ }^{\text {e }}$
}

Program Studi Magister Pendidikan Fisika, Pascasarjana, Universitas Negeri Semarang, J1. Kelud Utara III, Kota Semarang 50237.

Email: a)anindityadp@gmail.com, ${ }^{\mathrm{b})}$ sulhadipati@yahoo.com, ${ }^{\mathrm{c}}$ teguh_darsono@yahoo.com, ${ }^{\mathrm{d})}$ susipurwaningtyas@gmail.com, ${ }^{\mathrm{e})}$ cintiaagtasiaputri@yahoo.com

\begin{abstract}
Abstrak
Buah naga adalah tumbuhan yang berasal dari daerah beriklim tropis kering dan banyak dijumpai di Indonesia. Limbah kulit buah naga mengandung pigmen antosianin yang dapat dimanfaatkan sebagai pewarna lipstik alami. Pada penelitian ini diformulasikan sediaan lipstik dengan menggunakan kulit buah naga. Pengekstrakan kulit buah naga dilakukan dengan metode MAE. Komposisi ekstrak kulit buah naga pada lipstik yang dihasilkan divariasi $0 \%, 20 \%$, dan 26\%. Pengujian mutu dilakukan dengan uji stabilitas perubahan bentuk, uji rekat, uji $\mathrm{pH}$, serta analisis absorbansi pigmen warna. Hasil penelitian menunjukkan bahwa sediaan lipstik berbahan pewarna alami kulit buah naga yang dihasilkan memiliki bentuk yang stabil, $\mathrm{pH}$ mendekati $\mathrm{pH}$ bibir, dan absorbansi pigmen warna yang baik pada formulasi waktu ekstraksi 6 menit dan rasio pelarut 8:1.
\end{abstract}

Kata-kata kunci: Kulit Buah Naga, Pewarna Alami, Lipstik.

\begin{abstract}
Dragon fruit is a plant that comes from dry tropical climates and can be found easily in Indonesia. The dragon fruit wasted skin contains anthocyanin pigments that can be utilized as natural lipstick dyes. In this study, lipstick formulated using dragon fruit skin. The dragon fruit skin extraction was made by MAE method. The composition of dragon fruit skin extract on the resulting lipstick varied $0 \%, 20 \%$, and $26 \%$. The quality test was done by stability test of shape change, adhesive test, $\mathrm{pH}$ test, and color pigment absorbance analysis. The results showed that the dye lipstick made from natural dye skin of dragon fruit produced has stable form, $\mathrm{pH}$ close to lips' $\mathrm{pH}$, and good color pigment absorbance at 6 minute extraction and 8: 1 solvent ratio.
\end{abstract}

Keywords: Skin of Dragon Fruit, Natural Dyes, Lipstick. 


\section{PENDAHULUAN}

Literatur yang meneliti peran kosmetik dalam persepsi sosial telah menemukan bahwa, secara keseluruhan, makeup dikaitkan dengan evaluasi positif seorang wanita [1]. Penelitian terdahulu ini tampaknya menunjukkan bahwa wanita dengan riasan wajah menjadi lebih atraktif. Telah dilakukan uji dengan membatasi penggunaan kosmetik ke area wajah tertentu yang memberi efek daya tarik yang sama. Peneliti menemukan bahwa wajah wanita yang memakai make up penuh dinilai lebih menarik daripada wajah yang sama tanpa makeup, namun juga mendapati bahwa riasan bibir saja menghasilkan tingkat daya tarik rata-rata yang lebih tinggi daripada make up lain. Salah satu aspek yang mendapat perhatian adalah lipstik dan terutama warna bibir [2].

Lipstik adalah sediaan kosmetik yang digunakan untuk mewarnai bibir dengan sentuhan artistik sehingga dapat meningkatkan nilai estetika dalam tata rias wajah. Lipstik sering digunakan oleh para wanita, karena bibir dianggap sebagian besar penting dalam penampilan seseorang [3]. Namun, hasil pengawasan BPOM terdapat ratusan merk di pasaran tidak aman digunakan karena kebanyakan berasal dari bahan-bahan sintetik dan menimbulkan efek samping yang merugikan kulit, contohnya alergi dan iritasi. Oleh karenanya, untuk mendapatkan efek yang tidak merugikan dan hasil yang lebih aman untuk bibir, dibuat dengan bahan alami seperti tumbuh - tumbuhan atau buah - buahan.

Pewarna alami yang mempunyai potensi untuk dikembangkan antara lain yang berasal dari buah naga super merah (Hylocereus costaricensis), dengan warna merah yang sangat pekat, menunjukkan buah tersebut mengandung pigmen warna, yang dapat digunakan sebagai bahan pewarna alami pengganti bahan pewarna sintetik. Pada penelitian ekstrak buah naga super merah dengan metanol mengandung senyawa fenol dan betasianin [4].

Kulit dari buah naga merah merupakan limbah yang masih sangat jarang dimanfaatkan. Padahal, kulit buah naga masih mengandung senyawa antioksidan yang cukup tinggi. senyawa antioksidan mampu melawan oksidasi dalam tubuh [5]. Pemanfaatan kulit buah naga salah satunya dilakukan dengan pembuatan ekstraksi sehingga dapat dimanfaatkan sebagai bahan dasar beragam pangan dan kosmetik yang akan bermanfaat bagi kesehatan.

Ekstraksi adalah proses dimana unsur penyusun tanaman dihilangkan dengan menggunakan pelarut [6]. Microwave Assisted Extraction telah digunakan sebagai alternatif metode konvensional dalam ekstraksi unsur aktif dari bahan tanaman dan makanan. Hal ini didasarkan pada pemanasan kelembaban selektif dan cepat dalam sampel oleh gelombang mikro. MAE adalah proses penggunaan energi gelombang mikro untuk menghangatkan pelarut yang kontak dengan sampel agar memisahkan analit dari matriks sampel ke dalam pelarut. Gelombang mikro adalah gelombang elektromagnetik non-pengion frekuensi antara $300 \mathrm{MHz}$ sampai $300 \mathrm{GHz}$ dan diposisikan di antara sinar-x dan sinar inframerah dalam spektrum elektromagnetik. Metode MAE sangat berguna untuk ekstraksi sampel dengan asal tanaman. Kemampuan untuk cepat memanaskan campuran pelarut sampel melekat pada metode MAE dan merupakan keuntungan utama dari teknik ini [7].

\section{METODE PENELITIAN}

\section{Alat dan Bahan}

Alat yang digunakan adalah microwave daya $600 \mathrm{Watt}$, blender, neraca analitik, spektrofotometer UV-Spektrofotometri UV-VIS-NIR, gelas beaker, gelas ukur, kertas saring, spatula, $\mathrm{pH}$ meter

Bahan yang digunakan adalah cera alba, lanolin, vaselin, setil alcohol, carnauba wax, oleum ricini (costor oil), ekstrak kulit buah naga, oleum sakura, oleum apel, oleum stroberi, plopilen glikol, butyl hidroksitoluen (BHT), metil paraben (nipagin). 


\section{Ekstraksi Kulit Buah Naga}

Pembuatan ekstrak kulit buah naga dilakukan dengan metode MAE (Microwave Assisted Extractrion). Terdapat dua faktor perlakuan pada ekstraksi ini. Faktor perlakuan pertama adalah waktu pemanasan dengan microwave yang terdiri atas 3 level, yaitu 4 menit, 6 menit, dan 8 menit. Sedangkan waktu perlakuan kedua adalah rasio pelarut yang terdiri atas 2 level, yaitu 4:1 dan 8:1. Penentuan perlakuan terbaik didapat dengan uji absorbansi warna hasil ekstraksi kulit buah naga menggunakan Spektrofotometer Spektrofotometri UV-VIS-NIR. Analisis absorbansi ini bertujuan untuk mengetahui seberapa besar kemampuan sampel antosianin yang dihasilkan dari kulit buah naga untuk menyerap panjang gelombang sehingga sampel antosianin dapat digunakan sebagai pewarna lipstik.

\section{Formulasi Sediaan Lipstik}

Sediaan lipstik diformulasi dengan bahan yang tertera pada Tabel 1 [8].

Tabel 1. Komposisi sediaan lipstik dengan variasi massa ekstrak kulit buah naga sebanyak $0 \%, 20 \%$, dan $26 \%$.

\begin{tabular}{llcl}
\hline \multirow{2}{*}{ Komposisi } & \multicolumn{3}{c}{ Sediaan (gram) } \\
& I & II & III \\
\hline Cera alba & 10,86 & 8,566 & 7,864 \\
Lanolin & 2,286 & 1,801 & 1,655 \\
Vaselin & 9,716 & 7,655 & 7,036 \\
Setil alcohol & 1,714 & 1,351 & 1,241 \\
Carnauba wax & 1,428 & 1,126 & 1,034 \\
Oleum ricini & 2,286 & 1,801 & 1,655 \\
Ekstrak kulit buah naga & 0 & 6 & 7,8 \\
Oleum sakura/apel/stoberi & 0,15 & 0,15 & 0,15 \\
Propilen glikol & 1,5 & 1,5 & 1,5 \\
Butil hidroksitoluen & 0,03 & 0,03 & 0,03 \\
Metil paraben & 0,03 & 0,03 & 0,03 \\
\hline
\end{tabular}

Oleum ricini dimasukkan ke dalam beaker glass sebagai fase I. Bahan-bahan lain kecuali oleum sakura/apel/stoberi dilumerkan hingga suhu $70^{\circ} \mathrm{C}$ sebagai fase II. Fase I dan II dicampurkan perlahan-lahan dengan pewangi, serta dilakukan pengadukan pada beaker glass hingga homogen. Ekstrak kulit buah naga dicampurkan pada suhu $40^{\circ} \mathrm{C}$ dan dilakukan pengadukan kembali secara merata. Pada keadaan cair, campuran tersebut dicetak ke dalam cetakan lipstik.

\section{HASIL DAN PEMBAHASAN}

\section{Ekstrak Kulit Buah Naga}

Diperoleh ekstrak cair kulit buah naga dengan faktor perlakuan waktu dan rasio pelarut 4 menit 4:1, 4 menit 8:1, 6 menit 4:1, 6 menit 8:1, dan 8 menit 8:1. Pada faktor perlakuan 8 menit 4:1 didapatkan hasil ekstraksi kulit buah naga menggumpal sehingga sulit dilakukan analisis absorbansi warna dengan Spektrofotometri UV-VIS-NIR. 


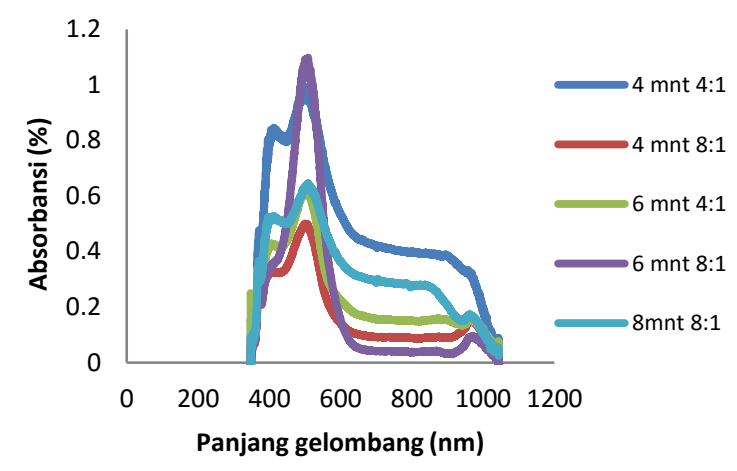

Grafik 1. Grafik hubungan panjang gelombang dengan absorbansi pada pigmen kulit buah naga merah serta variasi waktu dan perbandingan aquadest-asam sitrat.

Pada daerah panjang gelombang sekitar 400-600 nm nampak serapan yang begitu besar karena pada daerah itu sinar yang melalui pigmen memiliki energi yang cukup besar, atau lebih besar dari energy diam elektron pada pigmen. Energi tersebut diserap oleh elektron pada pigmen untuk melakukan transisi atau eksitasi elektron ke tingkat energi yang lebih besar. Absorbansi terjadi pada saat foton masuk bertumbukan langsung dengan atom-atom material dan menyerahkan energinya pada elektron atom. Foton mengalami perlambatan dan akhirnya berhenti sehingga pancaran sinar yang keluar dari material berkurang dibanding saat masuk ke material [9].

Hukum Beer menyatakan bahwa absorbansi cahaya berbanding lurus dengan konsentrasi dan ketebalan bahan, sehingga persamaannya dapat ditulis sebagai berikut

$A=e c l$

dengan $e$ adalah molar absorsitivitas untuk panjang gelombng tertentu, atau disebut juga sebagai koefisien ekstinsif (dalam $1 \mathrm{~mol}^{-1} \mathrm{~cm}^{-1}$ ), $c$ adalah konsentrasi molar (mol 1-1) dan 1 adalah ketebalan dari bahan yang dilintasi oleh cahaya $(\mathrm{cm})$. Berdasarkan grafik hubungan panjang gelombang dengan absorbansi pada pigmen kulit buah naga merah dan variasi waktu serta perbandingan pelarut diketahui bahwa hasil ekstraksi terbaik ditunjukkan oleh ekstraksi dengan waktu pemanasan 6 menit dan perbandingan pelarut 8:1.
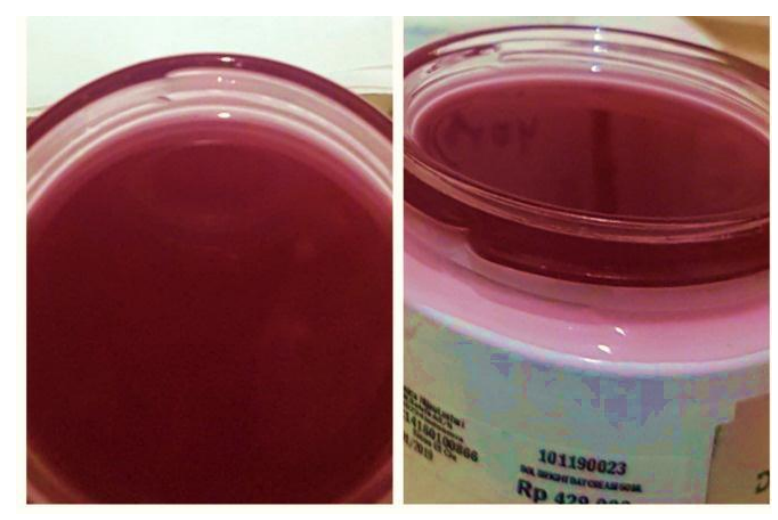

Gambar 1. Hasil ekstrak buah naga dengan perlakuan waktu 6 menit dan rasio pelarut 8:1.

\section{Sediaan Lipstik dari Ekstrak Kulit Buah Naga}


Sediaan lipstik berbahan pewarna alami dari ekstrak kulit buah naga diformulasikan dengan 3 variasi konsentrasi ekstrak.

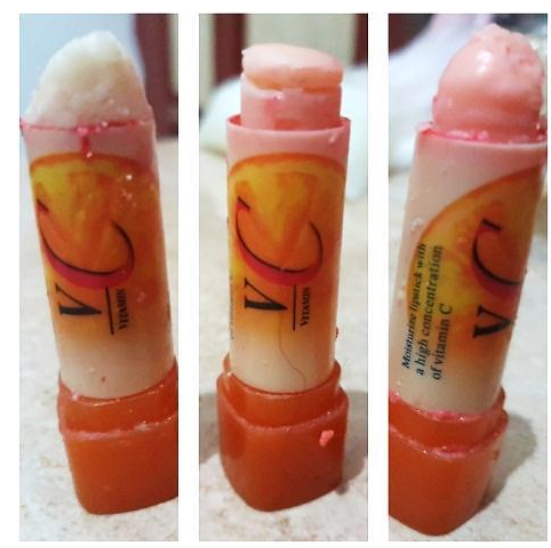

Gambar 2. Sediaan lipstik berbahan pewarna alami dari kulit buah naga dengan konsentrasi 0\%, 20\%, dan $26 \%$.

Konsentrasi yang pertama adalah sebesar 0\% atau tanpa dicampur dengan ekstrak kulit buah naga. Warna yang dihasilkan cenderung pucat. Pada formula kedua yang mengandung $20 \%$ konsentrasi ekstrak kulit buah naga menghasilkan warna yang lebih pink. Formula ketiga dengan konsentrasi ekstrak 26\% mempertegas warna pink lembut pada sediaan lipstik. Namun demikian, hasil uji rekat belum memenuhi harapan atau belum merekat dengan sempurna. Pengujian $\mathrm{pH}$ dilakukan dengan $\mathrm{pH}$ indikator menunjukkan hasil formula I memiliki $\mathrm{pH}$ 7, sedangkan formula II dan formula III memiliki PH rata-rata 5. Semakin tinggi konsentrasi kulit buah naga yang digunakan menyebabkan semakin rendahnya $\mathrm{pH}$ karena kulit buah naga bersifat asam. Sediaan lipstik yang dihasilkan memiliki $\mathrm{pH}$ yang mendekati $\mathrm{pH}$ bibir yaitu 4,0-6,5.

Pengamatan stabilitas bentuk lipstik bertujuan untuk memberikan pengenalan awal sediaan lipstik secara objektif berupa fisik, aroma, tekstur dan warna. Hasil pengamatan pada sediaan lipstik terlihat bahwa semua sediaan stabil secara fisik selama minggu ke-1 sediaan tidak berkeringat maupun tidak terbentuk kristal. Pengamatan aroma semua formula stabil sampai minggu ke-1. Pengamatan tekstur yang dilakukan pada formula I, formula II dan formula III mengalami ketidakstabilan tekstur dari halus menjadi tidak halus, hal ini terjadi disebabkan selama proses penyimpanan terjadi perubahan partikel dari sediaan yang menjadi kasar. Pengamatan warna sediaan lipstik untuk formula I warna stabil dari awal pembuatan, sedangkan formula II dan formula III mengalami ketidakstabilan warna. Ketidakcampuran pada proses pembuatan membuat warna pada sediaan lipstik sedikit memudar.

\section{SIMPULAN}

Zat pewarna alami untuk sediaan lipstik diperoleh dari ekstraksi kulit buah naga. Dari analisis absorbansi menggunakan Spektrofotometri UV-VIS-NIR, didapatkan hasil ekstraksi terbaik ditunjukkan oleh ekstraksi dengan waktu pemanasan 6 menit dan perbandingan pelarut 8:1. Formulasi sediaan lipstik yang dihasilkan menunjukkan bahwa kulit buah naga dapat dimanfaatkan menjadi bahan pewarna alami pada lipstik dengan bentuk stabil dan $\mathrm{pH}$ mendekati $\mathrm{pH}$ bibir.

\section{UCAPAN TERIMAKASIH}

Terimakasih kepada Allah SWT, orang tua, dosen pengampu mata kuliah Metodelogi Riset Sains, Panitia penyelenggara Seminar Nasional Fisika Universitas Negeri Jakarta, serta Laboratorium Fisika Universitas Negeri Semarang yang telah memberikan sarana dan prasarana untuk mendukung kegiatan penelitian ini serta kepada semua pihak yang telah membantu dalam kegiatan penelitian. 


\section{REFERENSI}

[1] Graham, J. A., \& Jouhar, A. J. The effects of cosmetics on person perception. International Journal of Cosmetic Science, 3, 199-210. 1981.

[2] Mulhern R., Fieldman G., Hussey T., Lévêque J.L., \& Pineau P. Do cosmetics enhance female Caucasian facial attractiveness. International Journal of Cosmetics Science, 25, 199-205. 2003.

[3] Wasitaatmadja, S. M. Penuntun Ilmu Kosmetik Medik. Jakarta: PenerbitUI Press. Hal. 28, 59-60, 182188. 1997.

[4] Umayah E. U dan Moch. Amrun H. Aktivitas Antioksidan Ekstrak Buah Naga (hylocereus undatus Britt. \& Rose). Universitas Jember: Jawa Timur.

[5] Olivianti, R. dan Zubaidah, E. Pengaruh Penambahan Garam dan Lama Penggaraman Terhadap Aktivitas Antioksidan Minuman Sari Pare (Momordica Charantia L). 2012.

[6] Agarwal SS, Paridhari M. Herbal Drug Technology. Published by University trust (India). Private limited, Hyderabad. 321- 326.

[7] Mandal V, Mohan Y, Hemalatha S. Microwave assisted extraction - A an innovative and promising extraction tool for medicinal plant research. PHcog rev. 1:1-17. 2007.

[8] Adliani, N., Nazliniwaty, Purba D. Formulasi Lipstik Menggunakan Zat Warna Dari Ekstrak Bunga Kecombrang. Journal of PHarmaceutics and PHarmacology, Vol. 1 (2): 87-94. 2012.

[9] Rehena, J.F., Uji Aktivitas Ekstrak Daun Pepaya (Carica papaya. LINN) Sebagai Antimalaria in vitro, Jurnal Ilmu Dasar, 2010. 